\title{
XINATGUAZIL (GENALGUACIL, SERRANÍA DE RONDA, MÁLAGA): CONTIGÜIDAD LINGÜÍSTICA EN POBLACIONES MORISCAS Y TOPONIMIA ÁRABE
}

\author{
SAlVAdor PeÑa Martín \\ Universidad de Málaga \\ Miguel Vega Martín \\ Archivo Diocesano de Málaga
}

Los documentos parroquiales de localidades habitadas por moriscos ofrecen con cierta frecuencia información sobre las circunstancias en que éstos vivían ${ }^{1}$, incluidos algunos aspectos de los usos lingüísticos en su entorno. Más en concreto, las actas parroquiales ofrecen a veces reflejo fidedigno de situaciones de contigüidad lingüística ${ }^{2}$ entre el castellano y el árabe muy avanzado ya el siglo XVI. Nos referimos a que la grafia con que aparecen en los documentos los nombres de esas poblaciones hace pensar que los párrocos autores de las anotaciones tenían ciertos conocimientos de lengua árabe, seguramente porque ésta no era del todo ajena a la generalidad de los habitantes de aquellas zonas, fueran moriscos o no.

Así, limitándonos a los libros parroquiales correspondientes a la Serranía de Ronda (Málaga) ${ }^{3}$, es de notar la grafía, varias veces repetida ${ }^{4}, \mathrm{Al} \mathrm{Gatu-}$ cin, para la localidad ahora llamada de Algatocín ${ }^{5}$. Como si quien hizo la anotación tuviera conciencia de la estructura morfonológica — que no la gráfica- del árabe, al separar el morfema de determinación al-. Conjetura esta, la de ciertos conocimientos del árabe, que parece reforzarse por el uso de la

1 Cfr. García-Arenal, M., «Las actas parroquiales de Comares (Málaga), 1564-1570» (1977), donde, entre otras, se atiende a cuestiones demográficas y antroponímicas.

${ }^{2}$ La noción de contigüidad lingüística procede de Uriel Weinreich, Languages in Contact: Findings and problems (1953).

${ }^{3}$ Que hemos consultado en el Archivo Histórico Diocesano de Málaga (AHDM, en adelante).

${ }^{4}$ Así aparece en el Libro Parroquial de Gaucín: AHDM, legajo 412, pieza n. ${ }^{\circ} 1$, folio 117, y por doquier en el propio libro de Algatocín: AHDM, legajo 142, pieza 1 (por ejemplo, folio 150). Esta grafia (Al Gatucin o al gatucin) alterna con otras, como algatuçin (legajo 412 , pieza . $^{\circ} 1$, folio 116 ).

5 Acerca de los problemas de la repoblación de la Serranía de Ronda, en general, y de las localidades que mencionamos en este estudio, véanse, entre otros, los trabajos de Acién Almansa, Ronda y su serranía en tiempo de los Reyes Católicos (1973), y Peinado Santaella, «La sociedad repobladora: el control y la distribución del espacio» (2000), así como las múltiples referencias de este último.

Al-Qanțara XXIV, 1 (2003) 203-2071 
vocal - $u$-, sobre todo si es que la palabra procede, como afirma Asín Palacios ${ }^{6}$, del gentilicio al- ${ }^{c} A t u \bar{u} \bar{s} \bar{i}$, "los ${ }^{c} A t u \bar{u} \bar{s}^{\prime}$.

En un sentido similar, resulta de interés cierta acta ${ }^{7}$ que transcribimos con su grafía original, añadiendo sólo entre corchetes lo elidido en abreviaturas, donde aparece el nombre de la población actualmente conocida como Genalguacil:

$\mathrm{p}$ [rimer]o de otubre de 1570 años baptize yo el b[achille]r solier cura aysabel hija de $\mathrm{p}$ [edr]o alaycar y de ysabel. su. $\mathrm{m}[\mathrm{u}] \mathrm{g}[\mathrm{er}]$. moriscos v[ecin]os de xinatguazil fueron padrinos al[onso] diaz y leonor sanchez su $\mathrm{m}[\mathrm{u}] \mathrm{g}[\mathrm{er}]$.

El b[achille]r Solier

Según el propio Asín Palacios ${ }^{8}$, que no alude a estadios anteriores del nombre actual, éste, Genalguacil ${ }^{9}$, procede del árabe $\hat{y}$ annat al-wazìr, que traduce: «huerto, jardín del visir». Hay que notar, además, que a continuación recoge un topónimo menor: el de Generalife (la finca de Granada), para el que da la etimología ŷannat al- ${ }^{c}$ arîf, que traduce: «huerto, jardín del Zambrero», y remite a Dozy, quien, aducía a su vez una frase de la Historia del rebelión y castigo de los moriscos, de Luis del Mármol, donde queda atestiguada una antigua grafia Ginalarife, con un primer elemento Gina- que nos interesa subrayar ${ }^{10}$. Antes aún que Dozy, Conde había tratado el topónimo Generalife, coincidiendo también en que el primer elemento es el árabe yanna ${ }^{11}$.

En efecto, puede hablarse de una etimología tradicional de Generalife para su primer elemento (pues respecto del segundo ha habido alguna otra opinión), que consiste en identificar Gina-/Gene- con el árabe ŷanna "huerto, jardín, paraíso". Así, Arié ${ }^{12}$ se hacía eco, sin darle crédito del todo, de la explicación según la cual se produjo una «déformation»a partir también de yannat al- ${ }^{c}$ arîf, que traduce «le jardin de l'architecte». Esto concuerda con el nombre que la finca recibía en árabe culto, según las fuentes literarias; así,

${ }^{6}$ Contribución a la toponimia árabe de España $\left(1944^{2}\right)$, s.v.

7 AHDM, legajo 412, pieza n. ${ }^{\circ} 1$, folio 58 vto.

${ }^{8}$ Contribución a la toponimia... (19442), s.v.

9 Se registra también, en los documentos que hemos consultado, entre la forma que comentamos, Xinatguazil, y la actual, Genalguacil, una forma intermedia: Genaguazil o Genaguasil, en anotaciones de la primera mitad del siglo XVIII (AHDM, Legajo 421, pieza n. ${ }^{\circ}$, folios 7 vto. y 17 vto.).

${ }^{10}$ Op. cit., s.v.; Asín Palacios remite a Dozy: Supplément aux dictionnaires arabes (1881), s.v. 'arîf, donde puede leerse la frase de Mármol: «guerta de Ginalarife, que quiere dezir guerta del Zambrero».

11 Aunque para el segundo da un étimo dificilmente sostenible, pues, según afirma en su Descripción de España (1799), 147, el topónimo es «corrupción de Gene-Xarif, huerto del Príncipe [...]»

${ }^{12}$ L'Espagne Musulmane au temps des Nașrides (1232-1492) (1973), 465, n. 3. 
por ejemplo, cuando Ibn Zamrak se refiere, en una de sus muwaššahăt, al lugar, que llama precisamente $\hat{y}$ annat al- $^{\mathrm{c}}$ arîf ${ }^{13}$.

Esta explicación tradicional: que el étimo del primer elemento Gena- (y sus variantes) de ciertos topónimos es ŷanna, comenzó a tambalearse al menos a partir de la aparición de un trabajo de Terés ${ }^{14}$ donde se documentaba la existencia de un gran número de topónimos cuyo primer elemento coincidía con el que nos interesa, pero en la forma ŷinān (o en alguna de sus variantes coloquiales), pero siempre con el significado singular de "huerto", aunque $\hat{y} i n a \bar{n}$ sea el plural de ŷanna en árabe culto. De este fenómeno, según apuntaba el propio Terés ${ }^{15}$, se tenía noticia por obras lexicográficas hispanas, tal como el Vocabulista de Pedro de Alcalá. Y nuevos estudios, como el de Corriente ${ }^{16}$ confirmaron después la coexistencia de una forma ŷanna y otra ŷinān (con sus respectivas variantes) pero siempre con significado singular ("huerto").

Con posterioridad, Díaz García y Barrios Aguilera ${ }^{17}$, al abordar buen número de topónimos granadinos, recogían, en la concienzuda entrada correspondiente a Ganilualid, la opinión de Terés y confirmaban que en árabe andalusí ŷinän (o yimin o yeneñn o incluso, en granadino, ŷeni) era un singular procedente de plural que había dado lugar a topónimos, como el estudiado.

Mientras tanto, la opinión de Asín Palacios seguía contando con reconocimiento, pues Corriente ${ }^{18}$, en su trabajo sobre el haz dialectal andalusí, recurría a los dos topónimos con que comenzábamos nosotros: Genalguacil («the minister's garden») y Generalife («the architect's garden»), para documentar cómo la marca de femenino - $t$, que en árabe culto se mantiene cuando forma parte del primer elemento de un sintagma de rección nominal, solía perderse en andalusí, con lo cual admitía el étimo ŷanna (y no ŷinān).

Así las cosas, el apunte parroquial que hemos transcrito más arriba creemos que muestra la pervivencia, en sociedades habitadas por moriscos, del procedimiento sintético de la rección nominal (concurrencia de dos nombres, el segundo en caso genitivo); siendo así que el árabe andalusí había desarrollado otros procedimientos analíticos (con uso de partículas, en lugar de los casos), según expone Corriente ${ }^{19}$. Y asimismo el mantenimiento de la $-t$ (en Xinatguazil), marca propia del sintagma de rección nominal en árabe culto. Queda también reflejado otro rasgo más habitual: la articulación [i]

\footnotetext{
13 El poema lo recoge al-Maqqarī: Nafh al-țīb, VII, 241. El mismo nombre, con la misma traducción, se recoge en la versión castellana de al-Lamha al-badriyya de Ibn

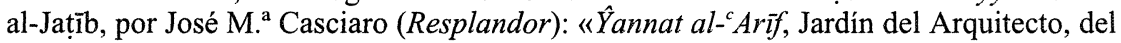
alarife [...]»: Historia de los reyes de la Alhambra, 136, n. 67.

${ }_{14}$ «Ŷ̀inān Dāwūd > Gerindote» (1970).

15 Op. cit., 203.

16 El léxico árabe andalusí según el «Vocabulista In Arabico» (1989), 72.

17 De toponimia granadina (1991), s.v. Ganilaulid, 189-192.

18 A Grammatical Sketch of the Spanish Arabic Dialect Bundle (1977), 87.

19 Árabe andalusí y lenguas romances (1992), 110.
} 
(en Xina-) por palatalización de la /a/, que habría sido asimilada por la consonante previa (seguramente articulada [ž] ${ }^{20}$.

Aun a falta de otros casos similares que refuercen nuestra hipótesis, no parece pues descabellada la posibilidad de que quienes concurrían al acto formal del bautismo y su anotación hacían uso de ciertos conocimientos de la lengua árabe, en su registro más elevado, el propio de la lengua escrita.

Para explicarlo, además de tener en cuenta la contigüidad lingüística entre el árabe y el romance en zonas de moriscos a lo largo del siglo XVI, está el tradicionalismo ${ }^{21}$ que, según parece, caracterizó muchas de las realizaciones lingüísticas de los moriscos (como marca distintiva de grupo marginado ${ }^{22}$ ). Tradicionalismo al que, en el caso de estos topónimos en Gena- (y sus variantes), puede que contribuyera el hecho de que el primer elemento, yanna "paraíso", era un término de evidentes resonancias coránicas: la «Casa de la Recompensa» (dār al-țawāb), según la expresión del exegeta granadino del siglo VIII h./XIV d.C., Abū Ḥayyān ${ }^{23}$.

\section{Referencias bibliográficas}

ABŨ HAYYĀN AL-ANDALUSĨ: Tafsīr al-Nahr al-Mādd, edición de Būrān al-Dannāwī y Hidyān al-Ḍannāwī, Beirut: Dār al-Ŷinān-Mu’assasat al-Kutub al-Ṭaqāfiyya.

ACIÉn AlmANSA, Manuel (1979): Ronda y su serranía en tiempo de los Reyes Católicos, Universidad de Málaga.

ARIÉ, Rachel (1973): L'Espagne Musulmane au temps des Nașrides (1232-1492), París: Boccard.

Asín PalaCios, Miguel (1944²): Contribución a la toponimia árabe de España, Madrid: CSIC.

CHAIKA, Elaine (1982): Language, the social mirror, Rowley: Newbury.

CONDE, Josef Antonio (1799): Descripcion de España de Xerif Aledris, conocido por el Nubiense, Madrid: Imprenta Real.

CORRIENTE, Federico (1977): A Grammmatical Sketch of the Spanish Arabic Dialect Bundle, Madrid: Instituto Hispano-Árabe de Cultura.

CORRIENTE, Federico (1989): El léxico árabe andalusi según el «Vocabulista In Arabico», Madrid: Universidad Complutense.

20 Por otro lado, hay que pensar que la pérdida de geminación consonántica - $n n$ - no se daba, sino que se trataría más bien de una dificultad de transcripción, en razón de que la geminación consonántica se mantenía en los registros no inferiores, según Corriente: Árabe andalusi... (1992), 64.

${ }^{21}$ Nos referimos a rasgos como el empleo de caracteres árabes al escribir en castellano o el uso de arcaísmos. Sobre todo esto, véase Feria García: La traducción fehaciente del árabe (2002), 49-60.

${ }_{22}$ El uso de rasgos lingüísticos destacados por parte de grupos sociales que sufren algún tipo de marginación ha sido, desde hace décadas y repetidas veces, descrito, por ejemplo, por Dittmar: Sociolinguistics (1976), 226-228, o Chaika: Language, the social mirror (1982), 111-120.

${ }^{23}$ Al-Nahr al-mädd I, 61 (comentando Corán II, 35). 
CORRIENTE, Federico (1992): Arabe andalusi y lenguas romances, Madrid: Fundación Mapfre.

DíAZ GARCÍA, Amador y BARrios Aguilera, Manuel (1991): De toponimia granadina, Universidad de Granada-Diputación Provincial de Granada (Chronica Nova).

DITTMAR, Norbert (1976): Sociolinguistics: A critical survey of theory and application; Londres: Arnold.

DOZY, R[einhart] (1881): Supplément aux dictionnaires arabes, Leiden: Brill.

FERIA GARCÍA, Manuel C. (2000-01): «Los moriscos y el uso de la aljamía», en Al-Andalus-Magreb (Universidad de Cádiz) 8-9, 299-323.

FERIA GARCÍA, Manuel C. (2002): La traducción fehaciente del árabe: Fundamentos históricos, jurídicos y metodológicos, Tesis Doctoral inédita, Universidad de Málaga.

GARCíA-ARENAL, Mercedes (1977): «Las actas parroquiales de Comares (Málaga), 1564-1570)», en Al-Andalus: Revista de las Escuelas de Estudios Árabes de Madridy Granada, 453-463.

IBN AL-JAȚIB (Resplandor): Historia de los reyes de la Alhambra: El resplandor de la luna llena (Al-Lamha al-badriyya), trad. José M. ${ }^{a}$ Casciaro Ramírez, Granada: Universidad-Legado Andalusí, 1998.

Al-MAQQARI Al-TILIMSĀNI, Aḥmad b. Muhammad (Nafhn): Naf̣h al-țîb min guṣn al-Andalus al-rațīb, ed. Ihsān 'Abbās, Beirut: Dār Șādir, 1968.

Peinado SANTAella, Rafael Gerardo (2000): «La sociedad repobladora: el control y la distribución del espacio», en Peinado Santaella, Rafael G. (ed.): Historia del Reino de Granada I: De los orígenes a la época mudéjar (hasta 1502), Granada: Universidad-El Legado Andalusí, 477-524.

TERÉs, Elías (1970): "Ŷinān Dāwūd > Gerindote», en Al-Andalus: Revista de las Escuelas de Estudios Arabes de Madrid y Granada XXXV, 203-209.

WeInREICH, Uriel (1953): Languages in Contact: Findings and Problems, Nueva York: Linguistic Circle. 